\title{
Larvicidal and Antagonistic Activities of Crude Leaf Extracts of Pyrethrum (Chrisanthemam: Compositae), Eucalyptus camaldulensis Sm. Myrtaceae, and Nicotiana tabaccum (Tobacco L.) (Solanaceae) Against Third Instar Larvae of the Malaria Vector, Anopheles gambiae s.s. Giles (Diptera: Culicidae.
}

\author{
Glenn O. Araka (Msc, Lead Researcher) ${ }^{1}$, John Ochora (PhD) ${ }^{2}$, Johnstone Wakhisi (PhD) ${ }^{3}$, \\ Dr. Festus Tolo (PhD) ${ }^{4}$, B.O. Khwa-Otsyula ${ }^{5}$ \\ ${ }^{1}$ Lecturer, Department of Environmental Health, School of Public Health, Moi University, Eldoret, Kenya
}

${ }^{2}$ Professor, Department of Botany, School of Biological Sciences, Jomo Kenyatta University of Agriculture and Technology (JKUAT), Nairobi, Kenya;

${ }^{3}$ Professor, Department of Medical Biochemistry, Moi University, Eldoret, Kenya

${ }^{4}$ Senior Researcher, Kenya Medical Research Institute (KEMRI), Nairobi, Kenya

${ }^{5}$ Professor of Surgery, Department of Surgery and Anesthesiology, School of Medicine, Moi University, Eldoret, Kenya

\begin{abstract}
Abtract: Crude leaf extracts of Pyrethrum, Eucalyptus camaldulensis and Nicotiana tabaccum (Tobacco) were individually and in combination tested for their larvicidal and antagonistic activities against third instar larvae of Anopheles gambiae s.s. Giles. The combination tests were targeted on antagonistic activities of the crude leaf extracts. Six different solvents were used namely Ethanol, Methanol, Dicholoromethane (DCM), Hexane, Ethyl Acetate and Aqueous for the preparation of crude leaf extracts from the plant leaves. The larval mortality of the third instar larvae of An. gambiae s.s. Giles was observed after 24 hours of exposure separately in control using 50, 100, 150, 200, 250, 300, 350 and 400 ppm. of crude leaf concentrations. For the individual crude leaf extracts all the six solvent extracts of the plants showed good larvicidal activity. The highest potency was recorded by DCM extract of pyrethrum (LC ${ }_{50}$ $164.68 \mathrm{ppm}, \mathrm{LC}_{90} 255.17 \mathrm{ppm}$ ) achieving $100 \%$ mortality of the larvae. Ethanol extract of pyrethrum also exhibited appreciable larvicidal activity at 167.78 ppm depicting 89.70\% larval mortality than same extracts of Nicotiana tabaccum (189.58 ppm) and E. camaldunsisis (210.15 ppm) causing $75.0 \%$ and $78 . .5 \%$ mortality respectively. The rest of the extracts i.e methanol, hexane, ethyl, acetate and aqueous exhibited a range of remarkable and varying activities i.e pyrethrum methanol 224. 45ppm, E. camaldulensis hexane $198.56 \mathrm{ppm}, \mathrm{N}$. tabaccum ethyl acetate $201.52 \mathrm{ppm}$ and pyrethrum aqueous $247.84 \mathrm{ppm}$ exhibiting mortality of $79.41 \%$, $73.65 \%$, $85.08 \%$ and $77.24 \%$ respectively. In combination activities for antagonism on a combination ratio of 1:1 (v.v) for all solvents used in crude leave extracts (30 treatments) it was observed that 12 combinations exhibited antagonistic activities (SF $<1), 15$ indicated synergistic activities while 3 combinations were neither antagonistic nor synergistic.
\end{abstract}

Keywords: Crude extracts, synergistic. antagonistic, solvents, mortality, individual activities , combination activities

\section{Introduction}

Milugo et al., (2013) describes the antagonistic effect of alkaloids and saponins on bioactivity in quinine tree from tissue samples of quinine tree (Rauvolfia caffra Sond) from a remnant forest in Kuria county of Western Kenya (1) Screening for phytochemicals in crude extracts from leaves and stem bark of $R$. caffra revealed the following classes of compounds: alkaloids, terpenoids, saponin, cardiac glycosides and steroids. This confirmed that $R$. caffra contained molecules known to be antioxidant activity. Although crude extracts from bark and leaf samples of $R$. caffra showed antioxidant activity (free radical inhibition) of $79 \%$ and $70 \%$ respectively analysis of fractions showed activity to vary with phytochemical composition. Fractions that included saponins, i.e alkaloids, steroids, terpenoids, cardiac glycosides saponins had a lowered activity of $58.99 \%$. Alkaloids only had 63\% activity, but fractions containing a combining of alkaloids and saponins exhibited the poorest antioxidant activity of $15 \%$. Alkaloids and saponins appeared to have antagonistic interaction, at least with regards to antioxidant activity. This potentially lowers their activity as antioxidants.

The co-toxicity factor $(\mathrm{CTF})$ calculated as $\mathrm{COF}=(\mathrm{O}-\mathrm{E} / \mathrm{E}) \mathrm{x}$ 100 , where $\mathrm{O}$ is observed \% mortality and $\mathrm{E}$ is expressed as $\%$ mortality categorizes result into three: A positive factor of $\geq-20$ which indicates potentiation, a negative factor of $\leq$ 20 indicates antagonism and the intermediate values of $>$ 20 to $<20$ indicate an additive effect. By comparing 


\section{International Journal of Science and Research (IJSR) \\ ISSN (Online): 2319-7064 \\ Index Copernicus Value (2013): 6.14 | Impact Factor (2015): 6.391}

mortalities obtained with the expected mortality of the mixture (50\%) the resultant synergistic/antagonistic factor (SF) could give an indication to the nature of the effect (i.e $\mathrm{SF}>1$ means synergism, SF $<1$ means antagonism; $\mathrm{SF}=1$ means no obvious effect) (2).

Synergy can result when the synergist (i) inhibits the detoxification of a toxin $(3, \mathbf{4}, \mathbf{5}, \mathbf{6})$, (ii) modifies an inactive compound rendering it toxic $(\mathbf{7}, \mathbf{8 , 9})$, (iii) enhances the penetration, transport or accessibility of a toxin to its target $(\mathbf{1 0}, \mathbf{4}, \mathbf{1 1}, \mathbf{1 2}, \mathbf{1 3}, \mathbf{1 4})$ or (iv) attacks two independent steps in a process, such as two stages in development or two steps in a biosynthetic pathway $(\mathbf{1 5 , 1 6 )}$. Antagonism can result when the reverse occurs. For example, an antagonism might modify a toxin rendering it inactive, or decrease the accessibility of a toxin to its target. Diawara et al. (1993) (17) used $x^{2}$ analysis to test for antagonistic effects of chemical combinations on larval mortality. The expected mortality of a chemical combination was determined from the observed mortality of each compound using the formula : $\mathrm{E}=\mathrm{Oa}+\mathrm{Ob}(1-\mathrm{Oa})$. The expected and observed values were analyzed by $x^{2}$, a significant difference from the expected being interpreted as synergy and other parameters such as larval weight and development time were analysed by ANOVA followed by a second unspecified test to determine which treatments differed and none of the ANOVA results were interpreted in terms of synergy or antagonism.

Greco et al. (1995) (18) have come up with isobolographic analysis method of determining synergistic and antagonistic interactions. In this null model, the combinations of two compounds, $\mathrm{A}$ and $\mathrm{B}$, are assumed noninteractive and the compounds A and B are two names for the same compound. Hence, in combination they act in additive manner. Additivity can be further generalized to two compounds that act independently on the same target such that their effects are additive. The combinations of $\mathrm{A}$ and $\mathrm{B}$ giving the same effect as A or B alone (the isoeffective dose combination) are represented by a straight, dashed line on an isobolograph that connects the effective doses of $\mathrm{A}$ and $\mathrm{B}$ when alone (Fig. 1). This line is called the zero -interaction isobole (Berenbaum, 1989) (19). The isobolograph (or isobologram) in Figure 1 depicts equivalent activities (GK.isoz = same + boli = effect) (Gessner, 1988) (20).

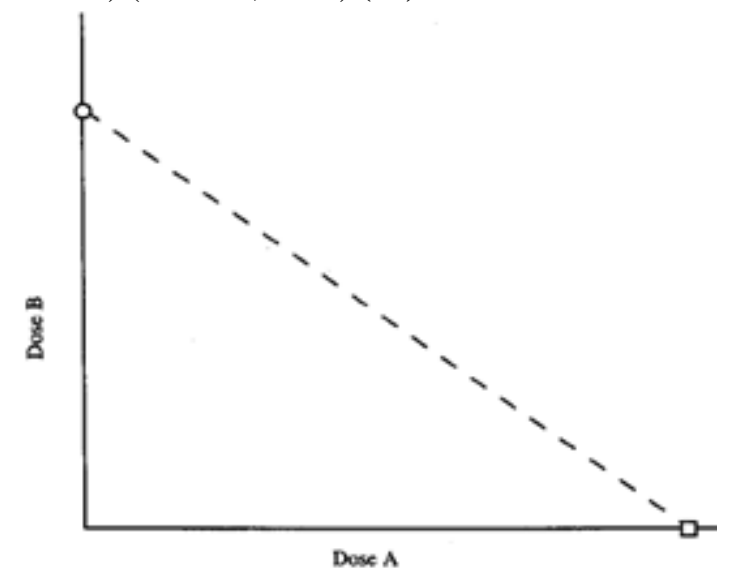

Figure 1: Zero-interaction isobole under the Loewe additivity null model

The dosages for A and B producing the same level of effect are plotted as the intercepts for each axis. The straight, dashed line represents the isoeffective dose combinations, or the combinations of $\mathrm{A}$ and $\mathrm{B}$ giving the same effect as either A or B alone.

Further as a hypothestical example, consider two hypothetical dose response curves for compounds A and B (Fig. 2). Use $\mathrm{LD}_{50}$ values (the dose killing $50 \%$ of the test organisms) for compounds A and B on the isobolograph, though any constant level of effect (e.g. $\mathrm{LD}_{90}, \mathrm{LD}_{25}$ ) can be used (Greco et al, 1995) (18).

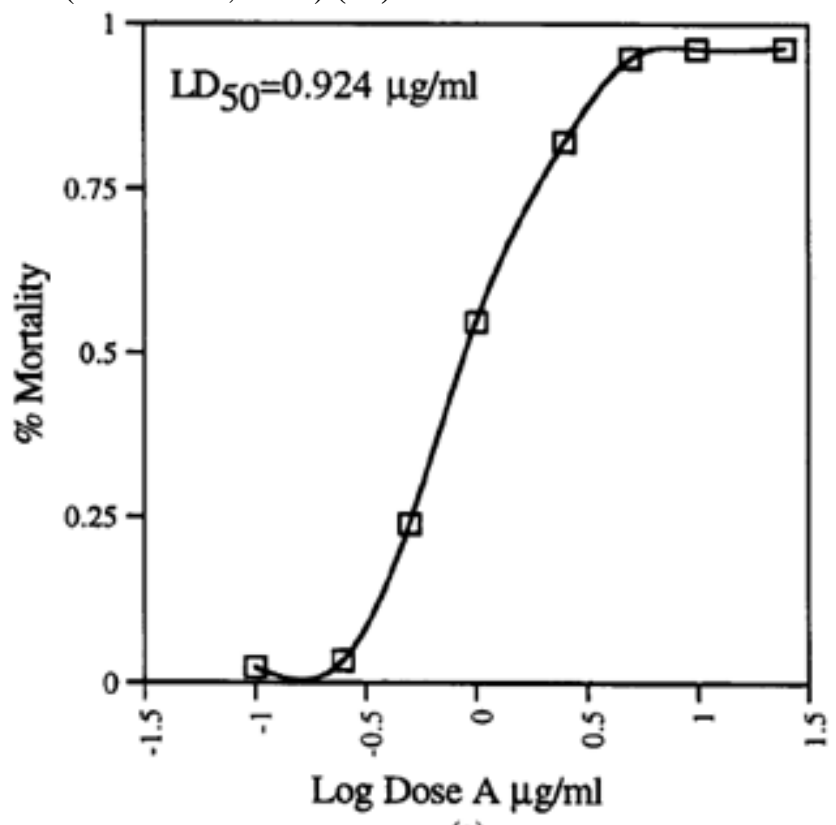

(a)

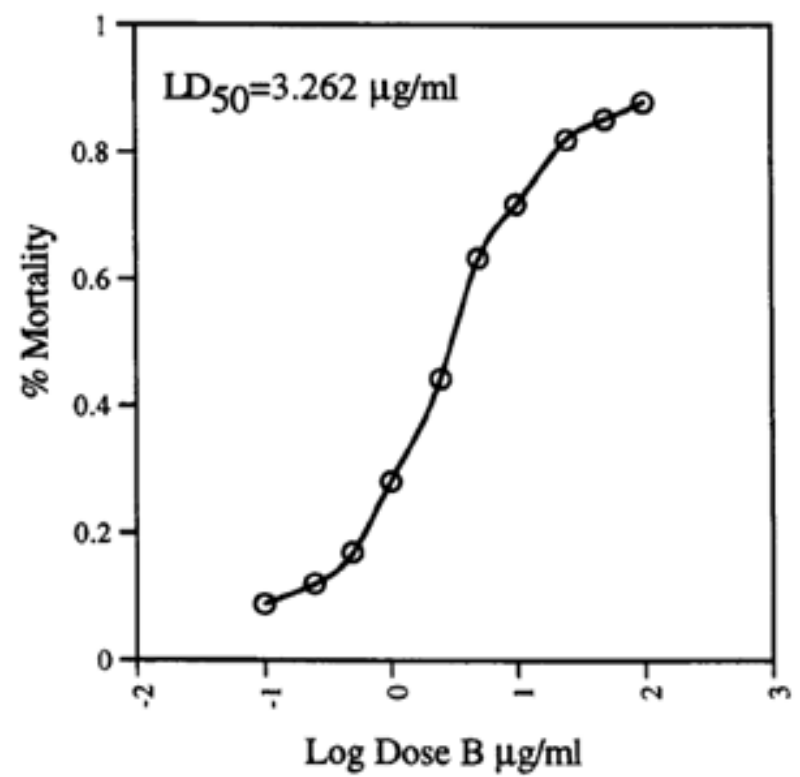

(b)

Figure 2: Hypothetical dose response curves for compounds $\mathrm{A}$ and $\mathrm{B}$.

On the isobolograph the $\mathrm{LD}_{50}$ values for each compound alone are plotted as the intercepts for each axis (Fig. 3). As in Fig.1 the straight, dashed line between the intercepts in Fig. 3 represents the isobole, or the null model: Loewe additivity with no interaction between the compounds. Thus any combination of $\mathrm{A}$ and $\mathrm{B}$ having concentrations that fall on this line should cause $50 \%$ mortality of the test organisms. If the $\mathrm{LD}_{50}$ value for a particular combination of 


\section{International Journal of Science and Research (IJSR) \\ ISSN (Online): 2319-7064 \\ Index Copernicus Value (2013): 6.14 | Impact Factor (2015): 6.391}

$\mathrm{A}$ and $\mathrm{B}$ lies above the zero- interaction line, $\mathrm{A}$ and $\mathrm{B}$ at that particular dose combination are said to be antagonistic ( Fig.3a). That is they are less potent in combination than one would expect based on their individual effective doses. If the $\mathrm{LD}_{50}$ value lies below the zero-interaction line, $\mathrm{A}$ and $\mathrm{B}$ are synergistic (Fig.3b). The combination is more effective than $\mathrm{A}$ and $\mathrm{B}$ are individually. Thus, a dose response curve resulting from various isoeffective combinations of $\mathrm{A}$ and $\mathrm{B}$ for a a synergistic interaction will be concave up and down the zero-interaction line ( Fig. 3b). Conversely, an antagonistic interaction will be represented by a concave down curve above the line ( Fig. 3a). The null model for the Loewe additivity is also represented by the equation: $d_{a} / D_{a}$ $+\mathrm{d}_{\mathrm{b}} / \mathrm{D}_{\mathrm{b}}=1$ ( Brenhaum, 1989 (19) ;Carter and Genings 1994) (21), where $d_{a}$ and $d_{b}$ are the concentrations of $A$ and

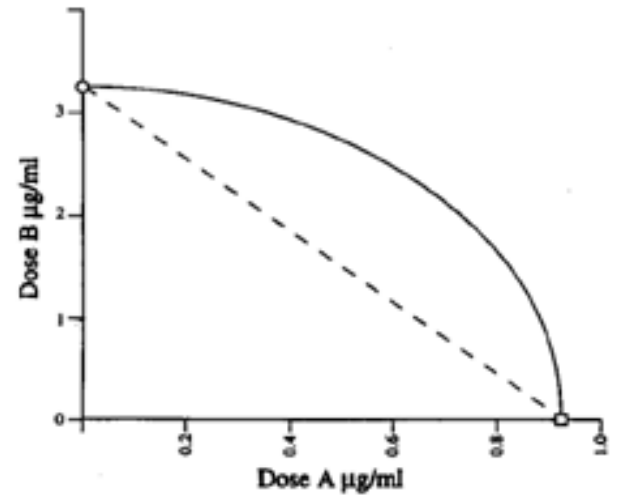

(a)
$\mathrm{B}$, respectively, used in combination and $\mathrm{D}_{\mathrm{a}}$ and $\mathrm{D}_{\mathrm{b}}$ are the individual concentrations of $\mathrm{A}$ and $\mathrm{B}$ producing a specific level of effect ( $L D_{50}$, for example). If the sum of the two ratios equals one, no interaction, or Loewe additivity, exists. If the sum is less than one, synergy is said to occur. If the sum is greater than one, antagonism is said to occur.

As a finality statistics can then be applied in order to determine the intensity of the synergistic or antagonistic interactions. The simplest method for representing the intensity of the interaction , a potency ratio, is illustrated in Figure 4 (Gressner1988) ( 20).

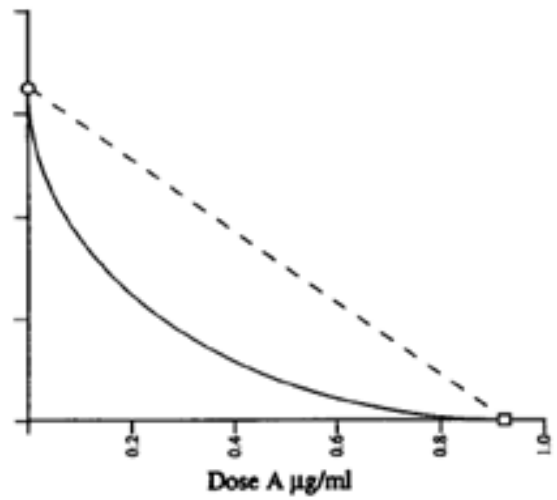

(b)

Figure 3: Isobolograph for compounds A and B

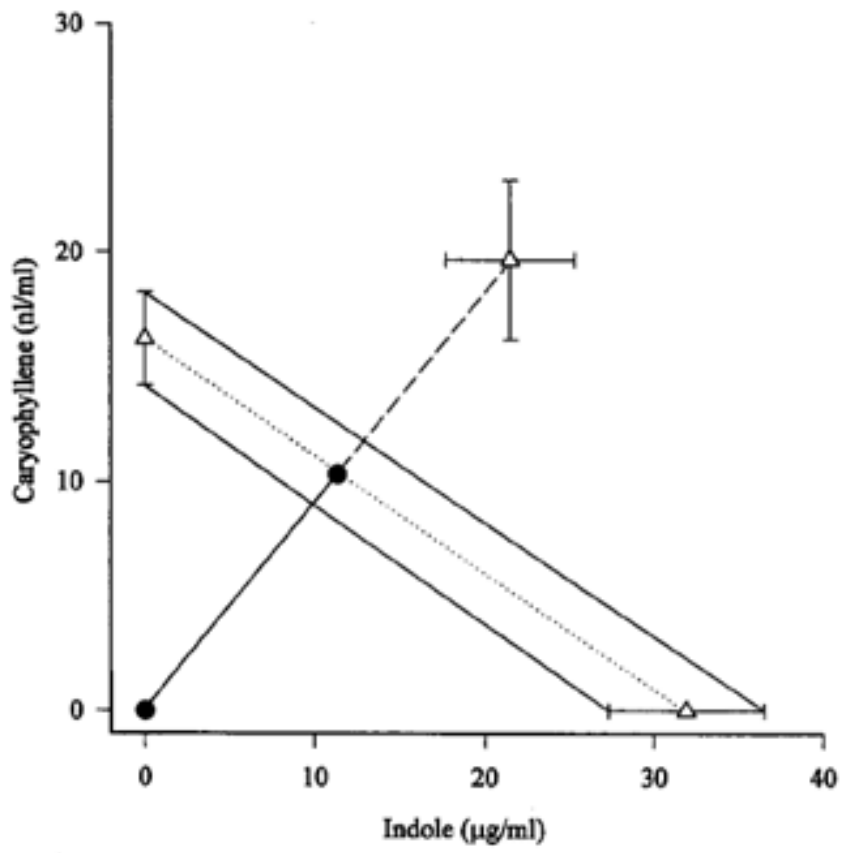

Figure 4: Isobolographic Analysis of a single Experiment

Isobolographic analysis of a single experiment indicating antagonism between indole and caryophylens. The dotted line is the zero interaction isobole constructed from experiments with each compound alone. The solid lines represent $95 \%$ confidence intervals. The third point above the zero-interaction isobole is the concentration of the combination that caused 50\% mortality along with the 95\% confidence intervals. The ratio of the two lines originating from the origin the solid plus the long-dashed line to the solid line is a measure of the intensity of antagonism.

\section{Materials and Methods}

\subsection{Collection of plant materials and extraction of essential oils}

A total of three plants were selected for use in these tests and were collected from various sources in Kenya in the month of May 2015. Pyrethrin (1 litre) as crude extract was purchased from Pyrethurm Board of Kenya (PBK), Stanley Mathenge Road, Nakuru, Kenya as a reserve extract. From the same Board $5 \mathrm{~kg}$ of dried pyrethrum flowers were as well purchased to be able to extract crude oil using similar solvent as those for Eucalyptus camaldulensis and Nicotiana tabaccum. PBK is a pyrethrum processing and marketing industry located 98 miles $(156.8 \mathrm{~km})$ east of Eldoret municipality and similar distance west of Kenya capital city, Nairobi. Eucalyptus leaves from mature gum trees (Eucalyptus camaldulensis) were collected from Molo subcounty, Kenya a distance of 68 miles $(108.8 \mathrm{~km})$ east of Eldoret and 30 miles $(48 \mathrm{~km})$ west of Nakuru. Tobacco leaves from the tobacco plant Nicotiana tabaccum were purchased from Mr. Meshack Wasike tobacco farm in Malakisi Location, Bungoma county, Kenya, a distance of 88 miles $(140.8 \mathrm{~km})$ west of Eldoret municipality and 15 miles $(24 \mathrm{~km})$ to the boarder of Kenya and Uganda. Pyrethrum which was purchased from PBK and extracted as crude oil using hexane was stored at $4^{0} \mathrm{C}$ in airtight amber or blue bottle until later when required for use. The dried pyrethrum flowers (Compositae cinerariaefolium one grown in Kenya) was extracted for pyrethrin mechanically using a commercial stainless steel blender, then $1 \mathrm{~kg}$ of powdered leaves was mercerated using six nonpolar to polar solvents: 


\section{International Journal of Science and Research (IJSR) \\ ISSN (Online): 2319-7064 \\ Index Copernicus Value (2013): 6.14 | Impact Factor (2015): 6.391}

dicholomethane (DCM), ethyl acetate, ethanol, methanol, hexane and aqueous and similarly were stored under $4^{0} \mathrm{C}$ until required for use. The leaves of Eucalyptus camaldulensis, and Nicotiana tabaccum (2kg each) were dried in shed for 20-30 days. The dried leaves were then separately powdered mechanically by the same commercial electrical stainless steel blender. One $\mathrm{kg}$ of each powdered leaves was extracted successfully by merceration using six nonpolar to polar solvents namely ethanol, methanol, dicholoromethane (DCM), ethyl acetate, hexane and water (aqueous). In each solvent the plant material was soaked for 48 hours at $35^{\circ} \mathrm{C}$ and filtered twice first using a fine cloth and then using Whatman number 1 filter paper $(12 \times 15 \mathrm{~cm})$ to obtain the extract and to the residue the same solvent was added again. The procedure was repeated twice to obtain maximum extract. The extracts were concentrated at reduced temperature using a rotary vacuum evaporator and stored in air tight amber or blue bottles at $4^{0} \mathrm{C}$ until when required for use. From the stock solutions of the extracts, varying concentrations of each extract were prepared and these concentrations were used for larvicidal bioassays. All chemicals used in this study were of extreme pure grade obtained from Kenya Medical Research Institute (KEMRI), Kisumu, Kenya.

\subsection{Mosquito Collection}

Larvae of Anopheles gambiae s.s. Giles mosquito were grown in a laboratory ( insectary) at the Human Anatomy Department, School of Medicine, Moi University, Eldoret. Using a mouth aspirator, male and female adult Anopheles gambiae s.s. Giles mosquitoes were collected into test tubes from Langas sub-urban area and taken for rearing in the laboretory. The mosquitoes were placed in cages (30 x $30 \mathrm{x}$ $30 \mathrm{~cm}$ ) in the ratio 3:1 male:female and were fed on $10 \%$ sucrose solution soaked in cotton wool. The rearing of larvae adult mosquitoes and larvae were maintained under favourable conditions (temperature $27 \pm 2^{\circ} \mathrm{C}$, RH $70-80 \%$. Larvae were fed in the laboratory with brewers yeast, dog biscuits and algae (3:1:1) on water surface.

\subsection{Larvicidal bioassays}

Larvicidal activity of each extract derived from the leaves of Pyrethrum, Eucalyptus camaldulensis and Nicotiana tabaccum (Tobacco) were tested. The test medium $(250 \mathrm{ml}$ glass beakers) was prepared by adding $1 \mathrm{ml}$ of appropriate dilution of essential oil in ethanol and mixed with $249 \mathrm{ml}$ of distilled water to make up $250 \mathrm{ml}$ of test solution (Dhamagadda et al, 2005) (39). Note that as the essential oil does not dissolve in water, it was first dissolved in ethanol (99.0\%). From the standard solution varying concentrations of each extract by dilution with distilled water, was prepared in various concentrations of 50, 100, 150, 200, 250, 300, 350 and $400 \mathrm{ppm}$ and these concentrations were used for larvicidal bioassays (An alternative to this method is to take $1 \mathrm{gm}$ of the concentrated plant extract and dissolve in $100 \mathrm{ml}$ of 1:1 acetate: diethyl sulphoxide (DMSO) and consider as $1 \%$ stock solution. From this stock solution varying concentrations as indicated above but expressed as percent could be prepared for use in larvicidal bioassays). Third instar of Anopheles gambiae s.s. Giles were exposed to these broad range of test concentrations of each leaf extract to determine the activity range of each extract. Susceptibility tests were carried out using WHO insecticide susceptibility test-kits (however, slightly modified) and standard procedures (1981) (40). The laboratory reared (27 $\pm 200 \mathrm{C}$ and $75 \pm 5 \% \mathrm{RH}$ ) late third instar larvae of Anolpheles gambiae s.s. Giles were used for experiments. By use of a mouth aspirator batches of 25 late third instar larvae were transferred to $300 \mathrm{ml}$ wide mouth disposable bowls containing serial concentrations of each plant extract. Four replicates were performed for each concentration. Larvae were confirmed dead when they failed to move after probing them with a needle at their cervical region. Moribund larvae were those incapable of rising to the surface when the test solutions were disturbed gently. Moribund larvae were counted after 24 hours of exposure (and added to dead larvae WHO, (2005) (41) and percentage mortality was calculated for each test as follows:-

Number of dead larvae $\div$ Number of larvae introduced $x$ 100 .

The final percentage was calculated from the average of four replicates. Solutions containing unchlorinated tap water and 1:1 v/v acetone: DMSO but without the plant extract, served as controls. The control mortalities were corrected by using Abbott's formula (1925) (42).

\subsection{Statistical Analysis}

The average larval mortality data were subjected to Probit analysis for calculating $\mathrm{LC}_{50}$ and $\mathrm{LC}_{90}$ and other statistics at 95\% fiducial limits of upper confidence limits (UCL) ad lower confidence limit (LCL) and chi-square values were calculated using the SPSS 18.0 (Statistical Package of Social Sciences) software - Finney,( 1971) (1).

\section{Methodology}

\subsection{Effects of individual crude leaf extracts.}

Three experiments were performed under individual crude leaf extracts activities:

i) Experiment 1: The effect of Pyrethrum crude leaf extract on the third instar larvae of Anopheles gambiae s.s. Giles

ii) Experiment 2: The effect of Eucalyptus camaldulensis crude leaf extract on the third instar larvae of Anopheles gambiae s.s. Giles

iii) Experiment 3: The effect of Nicotiana tabaccum crude leaf extract on the third instar of Anopheles gambiae s.s. Giles

The effects of Pyrethrum, E. camaldulensis and $N$. tabaccum crude leaf extracts on third instar larvae of An. gambiae s.s. Giles in the experiments 1, 2 and 3 above were investigated. Six solvents were used for each plant to extract the crude oil resulting to a total of 18 similar treatments for the three plants. Concentrations ranging from $0 \mathrm{ppm}$ (control), 50,100,150, 200, 250, 300, 350 and 400 ppm from each plant were made and used. Twenty (20) ml of each concentration for each plant was put into separate $50 \mathrm{ml}$ beakers and then twenty five (25) third instar larvae were dipped into the beakers. Mortality of the larvae was observed after 24 hour exposure by counting the number of dead third instar larvae. Larvae were confirmed dead when 


\section{International Journal of Science and Research (IJSR) \\ ISSN (Online): 2319-7064 \\ Index Copernicus Value (2013): 6.14 | Impact Factor (2015): 6.391}

they failed to move after probing them with a needle at their cervical region. Moribund larvae were those incapable of rising to the surface when the test solutions were disturbed gently. Calculations of the percentage of mortality of the larvae from three replications of each treatment determined lethal concentration $\left(\mathrm{LC}_{50}\right)$.

3.2 The efficacy of various solvent crude leaf extracts combination on the mortality of third instar larvae of Anopheles gambiae s.s. Giles

Three experiments were performed under crude leaf extracts combination activities:

3.2.1 Experiment 1: The effect of Pyrethrum crude leaf extract in combination with Eucalyptus camaldulensis crude leaf extract on third instar larvae of Anopheles gambiae s.s. Giles

3.2.2 Experiment 2: The effect of Pyrethrum crude leaf extract in combination with $N$. tabuccum crude leaf extract on the third instar larvae of Anopheles gambiae s.s. Giles

3.2.3 Experiment 3: The effect of Eucalyptus camaldulensis crude leaf extract, in combination with $N$. tabaccum crude leaf extract on the third instar larvae of Anopheles gambiae s.s. Giles.

The effects of the crude leaf extracts in their combination of Pyrethrum/E.camaldulensis $(\mathrm{P}+\mathrm{E})$ Pyrethrum $/ N$. tabaccum $(\mathrm{P}+\mathrm{T})$ and E. camaldulensis/N.tabaccum $(\mathrm{E}+\mathrm{T})$ on third instar larvae of An. gambiae s.s. Giles in the experiments 1, 2 , and 3 above were investigated. Six solvents were used for each plant to extract the crude oil. In the crude extract combinations a total of 30 similar treatments for the three plants were carried out. Concentrations ranging from $0 \mathrm{ppm}$ (control), 50,100,150, 200, 250, 300, 350 and 400 ppm from each plant were made and used. Twenty (20) ml of each concentration for each plant was put into separate $50 \mathrm{ml}$ beakers and then twenty five (25) third instar larvae were dipped into the beakers. Mortality of the larvae was observed after 24 hour exposure by counting the number of dead third instar larvae. Larvae were confirmed dead when they failed to move after probing them with a needle at their cervical region. Moribund larvae were those incapable of rising to the surface when the test solutions were disturbed gently. Calculations of the percentage of mortality of the larvae from three replications of each treatment determined lethal concentration $\left(\mathrm{LC}_{50}\right)$.

\section{Results and Discussion}

Individual crude leaf extract activities exhibited tremendous results as all solvents achieved far beyond 50\% mortality, ranging from pyrethrum DCM crude leaf extract 164.86 ppm (100 \% larval mortality), E. camaldulensis DCM crude leaf extract $168.65 \mathrm{ppm}$ (100\% larval mortality) as highest activities and ethyl acetate 260.56 ppm (65.55\% larval mortality). All crude leaf extracts were competitive in their activities.

Table 1: Individual crude leaf extract activities of six various solvents.

\begin{tabular}{|c|c|c|c|c|c|c|}
\hline Name of plant & Extract solvent & $\mathrm{LC}_{50}(\mathrm{ppm})$ & \multicolumn{2}{|c|}{ Fiducial limits } & Regression equation & Chi-square value (x2) \\
\hline & & & Upper & Lower & & \\
\hline \multirow{2}{*}{ Pyrethrum } & Ethanol & 187.78 & 179.78 & 196.53 & $0.7470+1.7758 \mathrm{x}$ & 4.5217 \\
& Methanol & 222.45 & 209.85 & 238.71 & $0.4684+1.9089 \mathrm{x}$ & 10.6452 \\
& DCM & 164.86 & 161.57 & 176.28 & $0.7336+1.7893 \mathrm{x}$ & 14.2584 \\
& Hexane & 230.66 & 214.79 & 252.67 & $0.5566+1.9098 \mathrm{x}$ & 19.5759 \\
& Ethylacetate & 227.56 & 219.77 & 269.96 & $0.4899+1.9078 \mathrm{x}$ & 19.5759 \\
& Aqueous & 247.84 & 233.37 & 267.72 & $0.6758+1.2123 \mathrm{x}$ & 18.6202 \\
\hline Eucalyptus & Ethanol & 210.15 & 193.88 & 232.07 & $0.7686+1.9694 \mathrm{x}$ & 4.6621 \\
(Camaldulensis) & Methanol & 197.46 & 189.61 & 208.69 & $0.4868+1.9227 \mathrm{x}$ & 13.256 \\
& DCM & 168.65 & 152.44 & 176.95 & $0.6975+1.9567 \mathrm{x}$ & 10.4532 \\
& Hexane & 198.56 & 181.66 & 220.45 & $0.7086+1.8685 \mathrm{x}$ & 9.5033 \\
& Ethylacetate & 260.56 & 240.77 & 289.96 & $0.05886+1.7825 \mathrm{x}$ & 14.0773 \\
& Aqueous & 259.58 & 239.87 & 288.87 & $0.05977+1.8365 \mathrm{x}$ & 6.7556 \\
\hline Nicotiana tabaccum & Ethanol & 189.58 & 181.50 & 298.42 & $0.7376+1.8898 \mathrm{x}$ & 3.5463 \\
& Methanol & 224.35 & 211.73 & 240.86 & $0.4988+1.8985 \mathrm{x}$ & 3.8642 \\
& DCM & 229.72 & 216.80 & 246.63 & $0.5878+1.9874 \mathrm{x}$ & 15.5740 \\
& Hexane & 235.85 & 221.25 & 240.53 & $0.5663+1.9096 \mathrm{x}$ & 4.6542 \\
& Ethylacetate & 201.52 & 191.00 & 213.84 & $0.6455+1.8990 \mathrm{x}$ & 14.0773 \\
\hline
\end{tabular}

Antagonistic activities i.e those with $\mathrm{SF}<1$ are shown in table 2 amongst them synergistic activities and those neither synergistic nor antagonistic. The results indicated antagonistic activities in 12 crude leaf extracts combinations, synergistic activities in 15 crude leaf extract combinations and 3 combinations were neither synergistic nor antagonistic.

From table 2 antagonistic activities i.e those with $\mathrm{SF}<1$ can be selected and listed as shown in Table 3 . 


\section{International Journal of Science and Research (IJSR) \\ ISSN (Online): 2319-7064}

Index Copernicus Value (2013): 6.14 | Impact Factor (2015): 6.391

Table 2: Antagonistic activities of the crude leaf extracts combination derived from 30 treatments.

\begin{tabular}{|c|c|c|c|c|c|c|c|c|}
\hline Plant & Ratio & $\begin{array}{c}\text { Combination solvent } \\
\text { extracts }\end{array}$ & Individu & $\mathrm{C}_{50} \mathrm{Ppm}$ & $\begin{array}{l}\text { Combination } \\
\mathrm{LC}_{50} \mathrm{ppm}\end{array}$ & \multicolumn{2}{|c|}{ SF } & effect \\
\hline Pyr. + Eucalyptus & $1: 1$ & $\begin{array}{c}\text { Ethanol +Aqueous } \\
\text { Methanol +Ethyl acetate } \\
\text { DCM + Hexane }\end{array}$ & $\begin{array}{l}187.78 \\
224.45 \\
164.86\end{array}$ & $\begin{array}{l}210.15 \\
260.56 \\
168.65\end{array}$ & $\begin{array}{l}152.85 \\
189.54 \\
127.85\end{array}$ & $\begin{array}{c}1.2285 \\
1.736 \\
1.2894\end{array}$ & $\begin{array}{l}1.3749 \\
1.3747 \\
1.3191\end{array}$ & $\begin{array}{l}S \\
S \\
S\end{array}$ \\
\hline $\mathrm{Pyr}+$ N. tabaccum & $1: 1$ & $\begin{array}{c}\text { Ethanol + Aqueous } \\
\text { Methanol +Ethyl acetate } \\
\text { DCM + Hexane }\end{array}$ & $\begin{array}{l}187.78 \\
224.45 \\
164.86\end{array}$ & $\begin{array}{l}189.58 \\
224.35 \\
229.72\end{array}$ & $\begin{array}{l}146.64 \\
232.66 \\
130.78\end{array}$ & $\begin{array}{l}1.2855 \\
0.9561 \\
1.2606\end{array}$ & $\begin{array}{l}1.2928 \\
0.9643 \\
1.7565\end{array}$ & $\begin{array}{l}\mathrm{S} \\
\mathrm{A} \\
\mathrm{S}\end{array}$ \\
\hline $\begin{array}{c}\text { E. camald.. }+N . \\
\text { tabaccum }\end{array}$ & $1: 1$ & $\begin{array}{c}\text { Ethanol +Aqueous } \\
\text { Methanol +Ethyl acetate } \\
\text { DCM + Hexane }\end{array}$ & $\begin{array}{l}210.15 \\
197.46 \\
168.65\end{array}$ & $\begin{array}{l}258.42 \\
201.52 \\
235.85\end{array}$ & $\begin{array}{l}242.80 \\
219.45 \\
135.55\end{array}$ & $\begin{array}{l}0.8655 \\
0.8998 \\
1.2442\end{array}$ & $\begin{array}{l}1.0643 \\
0.9182 \\
1.7399\end{array}$ & $\begin{array}{c}\text { SA } \\
\text { A } \\
\text { S }\end{array}$ \\
\hline Pyr. + E. camald. & $1: 1$ & $\begin{array}{c}\text { Methanol + Aqueous } \\
\text { DCM + Aqueous } \\
\text { DCM + Methanol } \\
\text { DCM +Ethyl acetate } \\
\text { Methanol +Ethyl acetate } \\
\text { Methanol + Hexane } \\
\text { Ethylacetate+ Hexane }\end{array}$ & $\begin{array}{l}224.45 \\
164.86 \\
164.86 \\
164.86 \\
224.45 \\
197.46 \\
227.56\end{array}$ & $\begin{array}{l}259.58 \\
259.58 \\
197.46 \\
260.56 \\
260.56 \\
198.56 \\
198.56\end{array}$ & $\begin{array}{l}201.55 \\
151.75 \\
118.65 \\
121.45 \\
230.50 \\
147.46 \\
236.65\end{array}$ & $\begin{array}{l}1.1136 \\
1.0864 \\
1.3895 \\
1.3574 \\
0.9651 \\
1.3391 \\
0.9616\end{array}$ & $\begin{array}{l}1.2879 \\
1.7106 \\
1.6642 \\
2.1454 \\
1.1304 \\
1.3465 \\
0.8390\end{array}$ & $\begin{array}{c}\text { S } \\
\text { S } \\
\text { S } \\
\text { S } \\
\text { SA } \\
\text { S } \\
\text { A }\end{array}$ \\
\hline Pyr + N. tabaccum & $1: 1$ & $\begin{array}{c}\text { DCM + Methanol } \\
\text { DCM + Ethyl acetate } \\
\text { Methanol + Aqueous } \\
\text { DCM + Aqueous } \\
\text { Methanol +Ethyl acetate } \\
\text { Methanol + Hexane } \\
\text { Ethylacetate+ Hexane }\end{array}$ & $\begin{array}{l}164.86 \\
164.86 \\
224.45 \\
164.86 \\
224.45 \\
224.45 \\
227.56\end{array}$ & $\begin{array}{l}224.35 \\
201.52 \\
259.58 \\
259.58 \\
201.52 \\
235.85 \\
235.85\end{array}$ & $\begin{array}{l}225.80 \\
160.75 \\
263.15 \\
155.80 \\
160.75 \\
231.65 \\
241.45\end{array}$ & $\begin{array}{l}0.7301 \\
1.0256 \\
0.8453 \\
1.0582 \\
1.0256 \\
0.9360 \\
0.9425\end{array}$ & $\begin{array}{l}0.9936 \\
1.2536 \\
0.9864 \\
2.6164 \\
1.2536 \\
0.9924 \\
0.9768\end{array}$ & $\begin{array}{l}\text { A } \\
\text { S } \\
\text { A } \\
\text { S } \\
\text { S } \\
\text { A } \\
\text { A }\end{array}$ \\
\hline $\begin{array}{l}\text { E. camald. }+N . \\
\text { tabaccum }\end{array}$ & $1: 1$ & $\begin{array}{c}\text { DCM + Methanol } \\
\text { DCM + Ethyl acetate } \\
\text { DCM + Aqueous } \\
\text { Methanol + Aqueous } \\
\text { Methanol + Hexane } \\
\text { Ethylacetate+ Hexane }\end{array}$ & $\begin{array}{l}164.65 \\
164.65 \\
164.86 \\
222.45 \\
197.46 \\
260.56\end{array}$ & $\begin{array}{l}224.35 \\
201.52 \\
259.58 \\
259.58 \\
235.85 \\
235.85\end{array}$ & $\begin{array}{l}149.35 \\
211.55 \\
158.43 \\
264.65 \\
220.75 \\
262.60\end{array}$ & $\begin{array}{l}1.1292 \\
0.7972 \\
1.0406 \\
0.8483 \\
0.8945 \\
0.9922\end{array}$ & $\begin{array}{l}1.5022 \\
0.9526 \\
1.6385 \\
0.9808 \\
1.0684 \\
0.8981\end{array}$ & $\begin{array}{c}\text { S } \\
\text { A } \\
\text { S } \\
\text { A } \\
\text { SA } \\
\text { A }\end{array}$ \\
\hline
\end{tabular}

Key: S- Synergistic; A - Antagonistic; SA- neither Synergistic nor Antagonistic

Of the five highest synergistic activity to note are the following combinations in their order: pyrethrum DCM extract + Eucalyptus camaldulensis methanol extract; pyrethrum DCM extract + Eucalyptus camaldulensis ethyl acetate extract; pyrethrum DCM extract + Eucalyptus camaldulensis hexane extract; pyrethrum DCM extract + Nicotiana tabaccum hexane extract and Eucalyptus camaldulensis DCM extract + Nicotiana tabaccum hexane extract. All these combinations yielded $100 \%$ larval mortality at the concentrations of $118.65,121.45,127.85$, 130.78 and 135.55 ppm respectively. These were indeed reduced concentrations compared to those used as individual extracts. From table 1 individual extracts activities are low: pyrethrum DCM (164.86 ppm); E. camaldulensis methanol (197.46 ppm); Eucalyptus camaldulensis ethyl acetate (260.56 ppm); and E. camaldulensis - hexane (198.56 ppm); and $N$. tabaccum hexane (235.85 ppm). This comparison raises the need for combination extracts as they proof to be economical. From the above highest synergistic activities it is observed that DCM extract of pyrethrum is a synergist (as it appears 5 times in the highest 5 activities shown above) and DCM extract of E. Camaldulensis is another synergist (as it appears once in the highest 5 activities shown above). Even in the lower activities DCM extract of all the plants is seen to be synergistically useful.

Table 3: Actual antagonistic activities of the crude leaf extracts derived from 30 treatments

\begin{tabular}{|c|c|c|c|c|c|c|c|c|}
\hline Plant & Ratio & Combination solvent & \multicolumn{2}{|c|}{ Concetration $\left(\mathrm{LC}_{50} \mathrm{ppm}\right)$} & Combination & \multicolumn{2}{|c|}{$\mathrm{SF}$} & Effect \\
\hline Pyrethrum + N. tabbacum & $1: 1$ & Methanol + Ethylacetate & 224.45 & 201.52 & 232.66 & 0.9561 & 0.9645 & A \\
\hline E. camald. $+N$. tabbacum & $1: 1$ & Methanol + Ethylacetate & 197.46 & 201.52 & 219.45 & 0.8998 & 0.9183 & A \\
\hline Pyrethrum + E. camald. & $1: 1$ & Ethylacetate +Hexane & 227.56 & 198.56 & 236.65 & 0.9616 & 0.8390 & A \\
\hline Pyrethrum + N. tabbacum & $1: 1$ & DCM +Methanol & 164.86 & 224.35 & 225.80 & 0.7301 & 0.996 & A \\
\hline Pyrethrum + N. tabbacum & $1: 1$ & Methanol +Ethylacetate & 222.45 & 201.52 & 243.40 & 0.9139 & 0.8279 & A \\
\hline Pyrethrum $+N$. tabbacum & $1: 1$ & Methanol + Hexane & 225.45 & 235.85 & 237.65 & 0.9360 & 0.9924 & A \\
\hline Pyrethrum + N. tabbacum & $1: 1$ & Ethylacetate +Hexane & 227.56 & 235.85 & 241.45 & 0.9425 & 0.9768 & A \\
\hline E. camald. + N. tabbacum & $1: 1$ & DCM +Ethylacetate & 168.65 & 201.52 & 211.55 & 0.7972 & 0.9526 & A \\
\hline E. camald. + N. tabbacum & $1: 1$ & Methanol +Ethylacetate & 197.46 & 201.52 & 210.30 & 0.9389 & 0.9583 & A \\
\hline E. camald. + N. tabbacum & $1: 1$ & Ethylacetate +Hexane & 260.56 & 235.85 & 262.60 & 0.9922 & 0.8981 & A \\
\hline Pyrethrum + N. tabbacum & $1: 1$ & DCM +Aqueous & 222.45 & 259.58 & 263.15 & 0.8453 & 0.9864 & A \\
\hline E. camald. + N. tabbacum & $1: 1$ & Methanol +Aqueous & 222.45 & 258.42 & 264.65 & 0.8483 & 0.9808 & A \\
\hline
\end{tabular}

From these combinations, it was observed that crude leaf extracts with the highest activity (Pyrethrum) are easily antagonized. From table 3 actual antagonists can be listed as follows:- 


\section{International Journal of Science and Research (IJSR) \\ ISSN (Online): 2319-7064 \\ Index Copernicus Value (2013): 6.14 | Impact Factor (2015): 6.391}

Table 4: List of Antagonists

\begin{tabular}{|c|l|c|}
\hline S/NO & Antagonistic crude leaf extract & $\begin{array}{c}\text { Lowered } \\
\text { concentration (ppm) }\end{array}$ \\
\hline 1 & Methanol of pyrethrum & 232.66 \\
\hline 2 & Ethyl acetate of $N$. tabaccum & 219.45 \\
\hline 3 & Ethyl acetate of pyrethrum & 236.65 \\
\hline 4 & Methanol of $N$. tabaccum & 225.80 \\
\hline 5 & Methanol of pyrethrum & 243.40 \\
\hline 6 & Hexane of pyrethrum & 237.65 \\
\hline 7 & Hexane of pyrethrum & 241.45 \\
\hline 8 & Aqueous of $N$. tabaccum & 263.15 \\
\hline 9 & Ethyl acetate of $N$. tabaccum & 211.55 \\
\hline 10 & Ethyl acetate of $N$. tabaccum & 210.30 \\
\hline 11 & Ethylacetate of E. camaldulensis & 262.60 \\
\hline 12 & Aqueous of $N$. tabaccum & 264.65 \\
\hline
\end{tabular}

\section{Conclusion}

Antagonistic act in opposition of synergistic. Antagonistic exhibit toxification of a toxin $(\mathbf{3}, \mathbf{4 , 5}, \mathbf{6})$ demodify an active compound rendering if untoxic $\mathbf{( 7 , 8 , 9 ) , ~ h i n d e r s ~ t h e ~}$ penetration, transport or accessibility of a toxin to its target $(4,10,11,12,13,14)$, and do not attack two independent steps in a process e.g stages in development or biosynthetic pathways $(\mathbf{1 5 , 1 6 )}$. In this respect antagonists can render mosquito programme control difficult and unsuccessful. It is important one to have prior knowledge on antagonistic activities before any crude leaf extract combinations is attempted to be used in mosquito control strategies. However, there is need for further studies in antagonism to come out clearly which compound(s) in each crude leaf extract is antagonistic to other compound(s) of the combining extract. Antagonistic compounds can render mosquito control programmes expensive since there will be unanticipated purchasing and repeated use of insecticides thus incurring large financial expenditure.

\section{References}

[1] Milugo,T.Z., Omosa,L.K., Ochanda,J.O., Owuor,B.O., Wamunnyokoli,F.A., Oyugi,J.O., and Ochieng,J.W., (2013). Antagonistic in the quinine tree (Rauvolfia caffra Sond); further evidence to support biotechnology in traditional medicinal plants. BMC complimentary and alternative medicine BMC Series open, inclusive and trusted 2013 13: 285. DOI: 10, 1186/1472-6882-13-285.

[2] Mansour, S.A., Bakr, R.F.A., Mohamed, R.I., and Hasaneen N.M., (2011). Larvicidal activity of some botanical extracts, commercial insecticides and their binary mixtures against the housefly, Musca domestica L. The Open Toxinology Journal, 2011, 4,1-13.

[3] Wilkinson, C.F., (1976). Insecticide synergism. Pp 195222 in Metcalf R. McKelvey Jr JJ (eds). The future for insecticides. NewYork: John Wiley and Sons.

[4] McKey, D., (1979), The distribution of secondary compounds within plants. Pp 55-133 in Rosenthal G.A., and Janzen D.H (eds) Herbivores: Their Interactions with Secondary Plant Metabolites. NewYork: Academic Press.

[5] Berenbaum, M.R., and Zangen. A.R., (1993). Furanocoumarin metabolism in Papilio Polyxenes: biochemistry, genetic variability and ecological significance. Oecologia 95:370-375.
[6] Zangeri A.R. in Ann C. Nelson and Thomas Kursar (1999). Interactions among plant defense compounds: a method for analysis. Chemoecology 9:81-92 (1999).

[7] Speneer K.C., (1988) Chemical mediation of coevolution in the Passiflora-Heliconious interaction Pp 167-240 in Spencer K.C., (ed) Chemical Mediation of Coevolution. San Diego/CA: Academic Press.

[8] Cipollin, M.L., Stiles, E.W., (1992). Antinfungal activity of ripe Ericacerus fruits: phenolic - acid interactions and palatability for dispersers. Biochem Syst Ecol. 20:501-514.

[9] Appel, H.M., (1993). Phenolics in ecological interactions: the importance of oxidation. $J$ Chem Ecol 19:1521-1552.

[10] Sun, Y.P., and Johnson, E. R., (1972). Quasi-synergism and penetration of insecticides. J Econ Entamol 55:349353.

[11] Applebaum, S.W., Birk, Y., (1979). Saponins. Pp. 539566 in Rosenthal G.A., Janzen, D.H., (eds). Herbivores: Their Interaction with Secondary Plant Metabolites, NewYork: Academic Press.

[12]Berenbaum, M., (1985). Brementown revisited: interactions among allelochemicals in plants. Recent Adv Phytochem 19:139-169.

[13] Kubo I., and Taniguchi, M., (1988). Polygodial, anantifungal potentiator. $J$ Nat Prod 51:22-29.

[14] Vaara, M., (1992). Agents that increase the permeability of the outer membrane. Microbial Rev 56:395-411.

[15] Georghiou, G.P., (1990). Overview of insecticides resistance. Pp. 18-41 in Green M.B., LeBaron, H.M., Moberg W.K., (ed). Managing Resistance to Agrochemicals. Washington/DC. American Chemical Society.

[16] Deminie, C.A, Bechtold, C.M, Stock, D., Alam, M., Djang, F., Balch, A.H., Chou T.C., Prichard, M., Colonno R.J., and Lin P.F., (1996). Evaluation of reverse transcriptase and protease inhibitors in two-drug combinations against human immunodeficiency virus replication. Antimicrob Agents chemother 40:13461351.

[17]Diawara, M.M., Trumble J.T., White K.K., Carson, W.G., and Martinez, L.A., (1993). Toxicity of linear furanocoumarins to Spodoptera exigua: evidence for antagonistic interactions. J Chem Ecol 19: 2473-2484.

[18] Greco, W.R., Bravo G., and Parsons J.C., (1995). The search for synergy: a critical review from a response surface perspective. Pharmacol Rev 47: 331-385.

[19] Berenbaum, M.C., (1989). What is synergy? Pharmacol Rev 41:93-141.

[20]Gessner, P.K., (1988). A straight forward method for the study of drug interactions: An isobolographic analysis primer. $J$ An Coll Toxicol >: 987-1012.

[21] Carter Jr, W.H., and Genning C., (1994). Analysis of Chemcial combinations: relating isobolograms to response surfaces. Pp. 643-653 in Yang R.S.H. (ed) Toxicology of Chemcial Mixtures. New York: Academic Press. 